\title{
Intraoperative Assessment of Gastric Sleeve Oxygenation Using Hyperspectral Imaging in Esophageal Resection: A Feasibility Study
}

\author{
Frank Schwandner Sebastian Hinz Maria Witte Mark Philipp \\ Clemens Schafmayer Eberhard Grambow
}

Department of General, Visceral, Vascular and Transplantation Surgery, University Medical Center Rostock, Rostock, Germany

\section{Keywords}

Esophageal cancer - Microcirculation · Perfusion monitoring · TIVITA ${ }^{\circledR}$ Tissue - Gastric sleeve tissue oxygenation before gastroesophageal anastomosis and might reduce the incidence of anastomotic failure in the gastrointestinal tract.

(C) 2020 The Author(s)

Published by S. Karger AG, Basel

\begin{abstract}
Introduction: Sufficient tissue oxygenation is essential for anastomotic healing in visceral surgery. Hyperspectral imaging (HSI) is a noncontact, noninvasive technique for clinical assessment of tissue oxygenation in real time. Methods: In this case series, HSI was used in 4 patients who were admitted for either esophageal cancer or cardiac carcinoma (AEG type I or II). Thoraco-abdominal surgical esophageal resection was performed after staging and neoadjuvant therapy. Intraoperative oxygenation of superficial $\left(\mathrm{StO}_{2}\right)$ and underlying tissue (NIR perfusion index) of the gastric sleeve were studied intrathoracic by means of the TIVITA ${ }^{\circledR}$ Tissue HSI camera. This was performed prior to esophagogastric anastomosis. The postoperative course, especially in view of surgical complications, was recorded. Results: Assessment of $\mathrm{StO}_{2}$ and NIR perfusion index was performed in 4 regions of interest per gastric sleeve, aboral and oral of the clinically determined resection line. It allowed the fast quantification of gastric oxygenation prior gastroesophageal anastomosis. Median $\mathrm{StO}_{2}$ aboral of the determined resection line was $69 \%$, while median $\mathrm{StO}_{2}$ in the oral part of the gastric sleeve was found at $53 \%$. In contrast, the median NIR perfusion index was similar aboral (80) and oral (82) of the resection line. In none of the 4 studied patients, an anastomotic failure appeared. Discussion/Conclusion: This report suggests that $\mathrm{HSI}$ is a feasible technique for intraoperative assessment of
\end{abstract}

karger@karger.com www.karger.com/vis

Karger ${ }^{\prime \prime}=$ BOPEN ACCESS
(C) 2020 The Author(s)

Published by S. Karger AG, Basel

This is an Open Access article licensed under the Creative Commons Attribution-NonCommercial-4.0 International License (CC BY-NC) (http://www.karger.com/Services/OpenAccessLicense), applicable to the onine version

\section{Introduction}

Curative surgical therapy of esophageal cancer and cardiac carcinoma (AEG type I or II) involves thoracoabdominal operation with resection of tumor and lymph nodes and preparation of the gastric sleeve for esophagogastric anastomosis. Thereby, anastomosis failure is a major complication. Especially in upper gastrointestinal surgery, anastomotic failure is associated with markedly increased morbidity and mortality for the patient, resulting in significant burden to the health system $[1,2]$. It requires a fast detection and respective surgical or endoscopic therapy. Reasons for anastomotic failure are multifactorial and include technical aspects like tension of the anastomosis, the used type of suture material, the technique of anastomosis, as well as patient-derived characteristics such as liver cirrhosis, smoking behavior, alcohol abuse, cachexia, systemic infections, immunosuppression, chronic kidney disease, arterial hypertension, or diabetes mellitus. Other extern circumstances affecting anastomotic healing are neoadjuvant radiation or chemotherapy, perioperative volume therapy, and blood transfusion [3]. However, impaired perfusion of gastroesophageal anastomoses or the gastric sleeve is one of the most important factors for anastomotic complications [4-6]. A 
Table 1. Characteristics of the 4 studied patients

\begin{tabular}{|c|c|c|c|c|}
\hline & Patient 1 & Patient 2 & Patient 3 & Patient 4 \\
\hline Age, years & 63 & 69 & 48 & 72 \\
\hline Gender & Male & Male & Male & Female \\
\hline Diagnosis & $\begin{array}{l}\text { Esophageal carcinoma } \\
\text { (squamous cell carcinoma) }\end{array}$ & $\begin{array}{l}\text { Cardiac carcinoma } \\
\text { AEG II (adenocarcinoma) }\end{array}$ & $\begin{array}{l}\text { Cardiac carcinoma } \\
\text { AEG I (adenocarcinoma) }\end{array}$ & $\begin{array}{l}\text { Cardiac carcinoma } \\
\text { AEG I (adenocarcinoma) }\end{array}$ \\
\hline $\begin{array}{l}\text { Neoadjuvant } \\
\text { therapy }\end{array}$ & Radiochemotherapy & $\begin{array}{l}\text { Chemotherapy } \\
(4 \mathrm{x} \text { cycle FLOT) }\end{array}$ & $\begin{array}{l}\text { Chemotherapy } \\
(6 \mathrm{x} \text { cycle FLOT) }\end{array}$ & $\begin{array}{l}\text { Chemotherapy } \\
\text { (4x cycle FLOT) }\end{array}$ \\
\hline Comorbidity & Arterial hypertension & $\begin{array}{l}\text { Arterial hypertension } \\
\text { Aortic valve insufficiency grade II } \\
\text { Mitral valve insufficiency grade II }\end{array}$ & - & $\begin{array}{l}\text { Arterial hypertension } \\
\text { Diabetes mellitus }\end{array}$ \\
\hline Operation & $\begin{array}{l}\text { Thoracoabdominal esophageal } \\
\text { resection, gastric sleeve, } \\
\text { cholecystectomy, jejunal } \\
\text { catheter }\end{array}$ & $\begin{array}{l}\text { Thoracoabdominal esophageal } \\
\text { resection, gastric sleeve, } \\
\text { cholecystectomy, jejunal catheter }\end{array}$ & $\begin{array}{l}\text { Thoracoabdominal esophageal } \\
\text { resection, gastric sleeve, } \\
\text { cholecystectomy, jejunal catheter, } \\
\text { atypical lung resection }\end{array}$ & $\begin{array}{l}\text { Thoracoabdominal esophageal } \\
\text { resection, gastric sleeve, jejunal } \\
\text { catheter }\end{array}$ \\
\hline Histology & $\begin{array}{l}\text { ypT0 pNo(0/18) } \\
\text { L0 V0 Pn0 R0 }\end{array}$ & $\begin{array}{l}\text { G2 ypT3 ypN1(2mi/27) } \\
\text { L0 V0 Pn0 R0 }\end{array}$ & $\begin{array}{l}\text { G3 pT3 pN1 }(2 \mathrm{mi} / 44) \\
\text { L1 V0 Pn0 R1 }\end{array}$ & $\begin{array}{l}\text { ypT0 ypNo(0/22) } \\
\text { L0 V0 Pn0 R0 }\end{array}$ \\
\hline
\end{tabular}

sufficient intraoperative evaluation of esophageal and gastric perfusion is essential to reduce the risk for anastomotic failure. Recently, hyperspectral imaging (HSI), a noninvasive, noncontact technique for quantification of tissue perfusion, was successfully tested for intraoperative assessment of bowel perfusion during colorectal resections $[7,8]$ and during esophagectomy [6]. Here, we report the results of the first 4 cases of intraoperative HSI measurement to analyze gastric sleeve perfusion intraoperatively during esophageal resection in our department.

\section{Materials and Methods}

\section{Patient Characteristics}

All 4 patients were admitted to the Department for General, Visceral, Vascular and Transplantation Surgery at the University Medical Center Rostock, Rostock, Germany, for operation with the diagnosis of esophageal cancer or cardiac carcinoma (AEG type I or II). The detailed patient characteristics are given in Table 1. In short, all cases were discussed in our multidisciplinary tumor board, and surgical resection after neoadjuvant therapy was recommended.

\section{HSI Camera System}

Oxygenation of the gastric sleeve was assessed by means of the TIVITA $^{\circledR}$ Tissue HSI camera (Diaspective Vision, Am Salzhaff, Germany). The TIVITA ${ }^{\circledR}$ Tissue provides precise reproducible parameters with high spatial resolution allowing for highly reliable determinations of the perfusion state of the measured tissue and for the analysis of spatial perfusion distribution. The camera system includes an internal push broom imaging spectrograph used for spectral data acquisition along the $\mathrm{x}$-axis that acquires a full spectrum for every point of the row in parallel, a high-quality infrared enhanced CMOS megapixel camera sensor, integrated in an intelligent camera with USB3-data transfer for high recording speed and an internal stepper motor moving the slit of the spectrograph at the first image plane of the optical setup along the y-axis to realize the image acquisition. With this system, a hyperspectral image can be acquired without the need of moving the camera or the patient. The distance between the camera and the investigated tissue is standardized at $50 \mathrm{~cm}$. This distance is defined by 2 LED lights (red and green) that fuse to 1 light point on the investigated tissue when the respective distance of $50 \mathrm{~cm}$ is reached. The measurement creates the so-called 3-dimensional hyperspectral data cube with the spatial $\mathrm{x}$ - and $\mathrm{y}$-axis as well as the spectral $\lambda$-axis. The hyperspectral data cube has an image resolution of $640 \times 480$ and comprises a spectral range from 500 to $1,000 \mathrm{~nm}$ with a resolution of $5 \mathrm{~nm}$ (100 spectral bands). The parameter calculation was developed by an empirical approach considering the known optical properties of tissues and blood and was calibrated by occlusion tests with healthy volunteers against a commercial tissue oximeter [9].

It is a noninvasive, noncontact imaging technique that enables spectroscopical measurement of tissue oxygenation over a larger area without the need for contrast agents or radiation. The TIVI$\mathrm{TA}^{\circledR}$ Tissue is designed to detect and measure the chromophores hemoglobin with its derivatives oxyhemoglobin $\mathrm{O}_{2} \mathrm{Hb}$ and deoxyhemoglobin $\mathrm{HHb}$ and water to provide a 2-dimensional map of oxygenation pattern ( $\mathrm{StO}_{2}$ and NIR perfusion index). $\mathrm{StO}_{2}$ and NIR perfusion index describe the relative oxygen saturation of hemoglobin in the microcirculatory system of the examined area in superficial tissues about $1 \mathrm{~mm}\left(\mathrm{StO}_{2}\right)$ and deeper tissues about a 3-mm depth (NIR perfusion index) [10].

\section{Intraoperative Procedure of HSI}

In principle, resection was performed as standard Ivor-Lewis operation. The abdominal preparation of the gastric sleeve was performed by means of the Echelon Flex Powered stapler (Johnson \& Johnson, New Brunswick, NJ, USA). After positioning of the gastric sleeve in the thorax, tissue perfusion was assessed by means of HSI before shortening it to the optimal length for the esophagogastric anastomosis. The resection line for the anastomosis was determined by clinical examination of the gastric sleeve and was not affected by the assessed oxygenation parameters. The oxygenation was assessed in 4 regions of interest (ROI) with a standardized diameter of 30 pixel. They were positioned oral and aboral of the clinically defined resection line of the gastric sleeve. The dis- 
tance between the ROIs was chosen individually with respect to the length of the gastric sleeve. After the HSI measurement, the transection of the sleeve was also performed using an Echelon Flex Powered stapler, and the anastomosis was created using a $25-\mathrm{mm}$ Echelon Circular Powered stapler (Johnson \& Johnson, New Brunswick, NJ, USA).

\section{Results}

\section{Patient 1}

A 63-year-old male patient with a low-grade squamous cell carcinoma of the esophagus was discussed in our multidisciplinary tumor team and a neoadjuvant chemoradiotherapy prior surgical tumor resection was conducted. As a comorbidity, an arterial hypertension existed. After a cumulative radiotherapy with $41.4 \mathrm{~Gy}$ and carboplatin/paclitaxel treatment, the restaging after neoadjuvant therapy revealed no metastases. The preoperative esophagoscopy showed a persistent stenosis $29 \mathrm{~cm}$ from the incisors. Therefore, a thoracoabdominal esophageal resection was indicated and performed according to standard. After positioning the gastric sleeve in the thorax, HSI was performed (Fig. 1A). Postoperatively, the patient was admitted to the intensive care unit (ICU) for 3 days. The postoperative course was uneventful. Histologic analysis defined the tumor stage ypT0 pN0 (0/18) L0 V0 Pn0 R0. In the postoperative tumor board conference, an oncologic surveillance was recommended. The patient was discharged 19 days after the surgery.

\section{Patient 2}

A 69-year-old male patient with a cardiac carcinoma AEG II was discussed in our multidisciplinary tumor team, and neoadjuvant chemotherapy (4x cycle FLOT) was conducted prior to the surgical tumor resection. As a comorbidity, arterial hypertension, aortic valve insufficiency grade II, and a mitral valve insufficiency grade II existed. A thoracoabdominal esophageal resection was indicated and performed according to standard as described for patient 1 . Tissue perfusion was assessed like in patient 1 by means of HSI (Fig. 1B). Postoperatively, the patient was admitted to the ICU for 2 days. The postoperative course was uneventful except for a wound healing disorder, which was treated conservatively. Histologic analysis defined the tumor stage G2 ypT3 ypN1(2mi/27) L0 V0 Pn0 R0. In the postoperative tumor board conference, an adjuvant chemotherapy was recommended. The patient was discharged 11 days after the surgery.

\section{Patient 3}

A 48-year-old male patient with a cardiac carcinoma AEG I was discussed in our multidisciplinary tumor team, and a neoadjuvant chemotherapy (6x cycle
FLOT) was conducted prior to surgical tumor resection. No comorbidity existed. Thoracoabdominal esophageal resection was indicated and performed according to standard and then tissue perfusion was assessed by means of HSI (Fig. 1C). Postoperatively, the patient was admitted to the ICU for 22 days. The postoperative course was characterized by an acute respiratory distress syndrome (ARDS) with pneumonia followed by dilatative tracheotomy. A gastroscopy due to increased infection signs on the 7 th postoperative day showed an inconspicuous anastomosis. Histologic analysis defined the tumor stage G3 pT3 pN1(2mi/44) L1 V0 Pn0 R1. Due to the R1 situation, the postoperative tumor board conference recommended a local radiation therapy. The patient was discharged 32 days after the surgery.

\section{Patient 4}

A 72-year-old female patient with a cardiac carcinoma AEG I was discussed in our multidisciplinary tumor team, and a neoadjuvant chemotherapy (4x cycle FLOT) was conducted prior to surgical tumor resection. As comorbidities, diabetes mellitus (dietary) and arterial hypertension existed. Thoracoabdominal esophagus resection was indicated and performed according to standard and also tissue perfusion was assessed by means of HSI (Fig. 1D). Postoperatively, the patient was admitted to ICU for 9 days. The postoperative course was characterized by a pneumonia and chyle fistula, both treated conservatively. A gastroscopy due to increased infection signs on the 6th postoperative day showed an inconspicuous anastomosis. Histologic analysis defined the tumor stage ypT0 ypN0(0/22) L0 V0 Pn0 R0. In the postoperative tumor board conference, a completion of adjuvant chemotherapy was recommended. The patient was discharged 25 days after the surgery.

\section{Intraoperative Oxygenation Assessment}

The intraoperative oxygenation parameters $\mathrm{StO}_{2}$ and NIR perfusion index are shown in Figure 1. Referring to the defined resection line, quantification of both parameters in the aboral part of the gastric sleeve revealed $\mathrm{StO}_{2}$ range from 51 to $84 \%$ and a NIR perfusion index range from 70 to 89 in all 4 patients. The median $\mathrm{StO}_{2}$ in the aboral part was $69 \%$ (25\% percentile: $65.5 \%$; $75 \%$ percentile: $75.5 \%)$, the median NIR perfusion index was 80 (25\% percentile: $74.5 ; 75 \%$ percentile: 84.5$)$. In contrast, the oxygenation parameters oral of the resection line were found lower, with $\mathrm{StO}_{2}$ ranging from 40 to $71 \%$ and NIR perfusion index ranging from 70 to 83 (Table 2). Here median $\mathrm{StO}_{2}$ was $53 \%$ (25\% percentile: $51 \%$; $75 \%$ percentile: $67 \%$ ), median NIR perfusion index was found at 82 (25\% percentile: $80 ; 75 \%$ percentile: 83 ). 

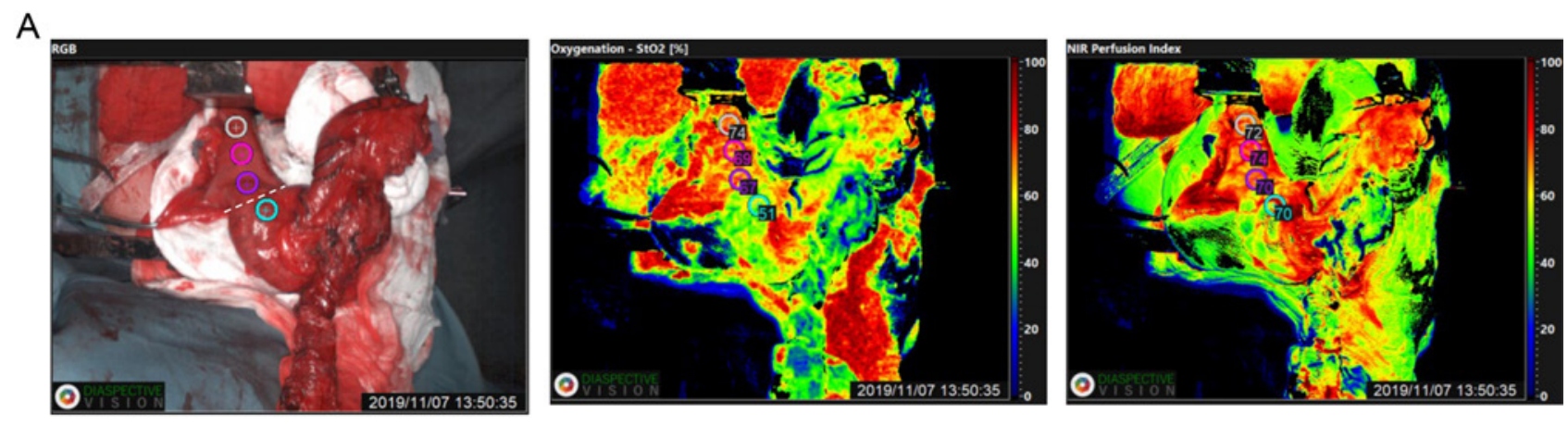

B
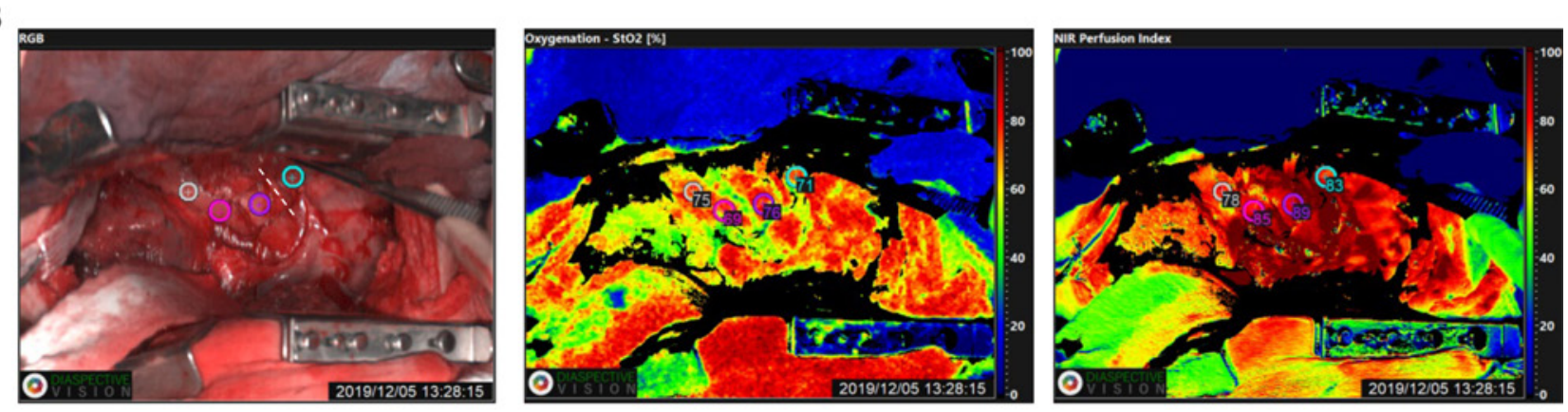

C
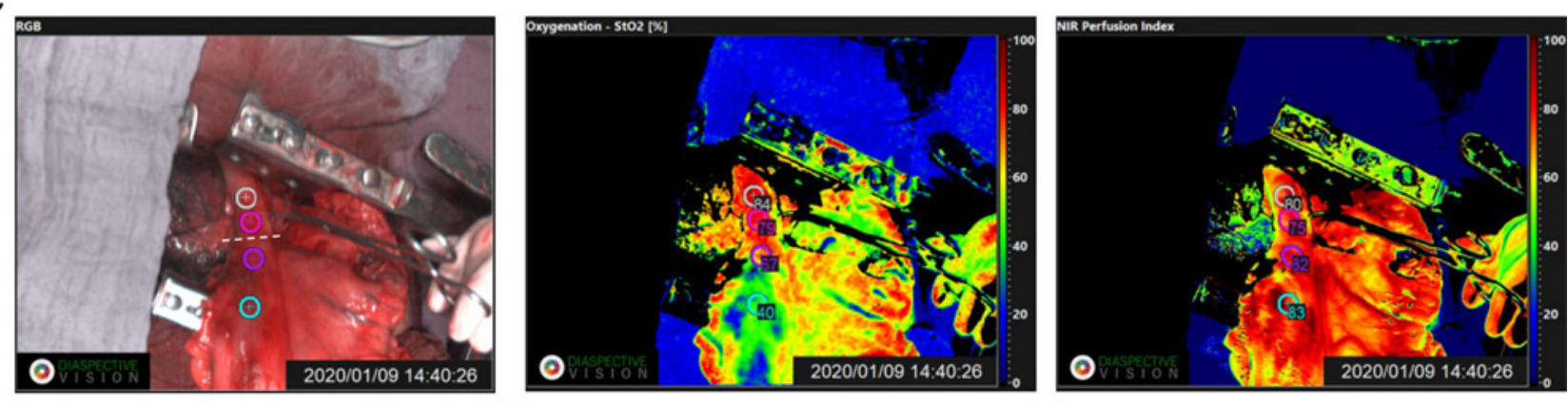

$\mathrm{D}$
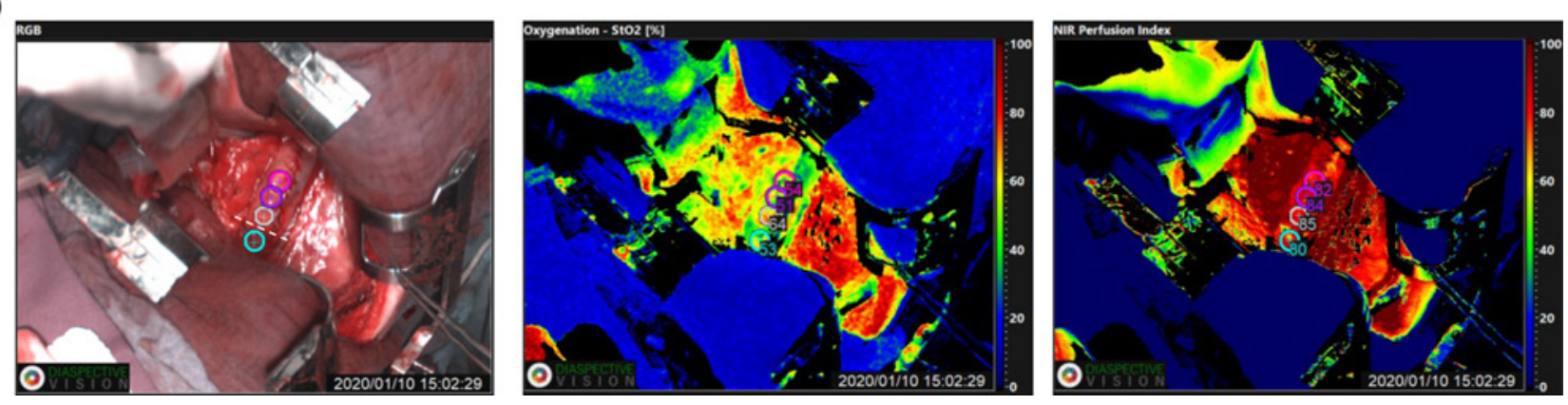

Fig. 1. Hyperspectral analysis of gastric sleeve perfusion. In all 4 patients (A-D, respectively), intraoperative redgreen images show the gastric sleeve before resection and subsequent esophagogastric anastomosis. The clinically defined resection line is shown dashed. Hyperspectral assessment included analysis of superficial $\left(\mathrm{StO}_{2}\right)$ and deeper (NIR perfusion index) tissue oxygenation in 4 ROIs.

\section{Discussion/Conclusion}

HSI bears the benefits of a noninvasive, mobile, easy to use technique that can visualize tissue oxygenation saturation in real time without the need for any contrast agents. This could be a benefit compared to other methods for intraoperative assessment of perfusion during esophagectomy like the indocyanine green (ICG) fluorescence technique [11]. ICG angiography indirectly measures tissue perfusion by emission of excitation of the ex- 
Table 2. Intraoperative oxygenation parameter of the gastric sleeve

\begin{tabular}{lll}
\hline & $\mathrm{StO}_{2}, \%$ & $\begin{array}{l}\text { NIR perfusion } \\
\text { index }\end{array}$ \\
\hline $\begin{array}{ll}\text { Patient } 1 \\
\text { Aboral }\end{array}$ & 74 & 72 \\
& 69 & 74 \\
Oral & 67 & 70 \\
\hline Patient 2 & 51 & 70 \\
Aboral & & \\
& 75 & 78 \\
Oral & 69 & 85 \\
\hline Patient 3 & 76 & 89 \\
Aboral & 71 & 83 \\
Oral & & \\
& 84 & 80 \\
\hline Patient 4 & 79 & 85 \\
Aboral & 67 & 83 \\
& 40 & 82 \\
Oral & & 84 \\
\hline
\end{tabular}

$\mathrm{StO}_{2}$ and NIR perfusion index were assessed in the gastric sleeve aboral and oral from the clinically defined resection line.

ogenously supplied fluorescent dye. In contrast, HSI allows direct quantification of tissue oxygenation. The hyperspectral dataset as well as the quantitative analysis are stored in the camera system which is an important aspect for postoperative recapitulation of intraoperative tissue perfusion and might have legal relevance in future when it comes to the question of intraoperative tissue perfusion. Due to these aspects, the camera system is actually tested in different clinical settings. It comprises analysis of wounds to predict wound perfusion and healing $[12,13]$, detection of brain cancers $[14,15]$, depth assessment of thermal wounds [16], and microcirculatory effects of postoperative therapy in Dupuytren's disease [17]. Our own group previously showed the feasibility of HSI for detection of peripheral artery disease [10].

In visceral surgery, the TIVITA ${ }^{\circledR}$ Tissue was already used for evaluation of colon perfusion and during esophagectomy [6, 7]. Jansen-Winkeln et al. [7] have recently showed that HSI allows precise quantification of bowl perfusion in colorectal surgery. Therefore, it could be used to determine of the optimal resection margin with respect to tissue oxygenation. The technical details of this camera system were previously described in detail [10, 18]. Intraoperative assessment of this parameters took about $1 \mathrm{~min}$, including positioning of the camera, record of the hyperspectral data, and quantification of $\mathrm{StO}_{2}$ and
NIR perfusion index by means of the software TIVITA ${ }^{\circledR}$ suit that is included in the camera system. The intraoperative gained data allowed a direct visualization and quantification of the gastric sleeve. As indicated by the figure, HSI analysis was performed after positioning of the sleeve in the thorax (Fig. 1). The circular ROI for quantification of $\mathrm{StO}_{2}$ and NIR perfusion index of the gastric sleeve were defined after clinical determination of the resection line for subsequent esophagogastric anastomosis. Over all 4 patients, $\mathrm{StO}_{2}$ was found lower in the resected oral part of the gastric sleeve. In the aboral part of the gastric sleeve, the median $\mathrm{StO}_{2}$ in this case series was comparable to the median $\mathrm{StO}_{2}$ described by Koehler et al. [6] in the group without ischemic preconditioning. Although the studied patient group is small, this accounts for the comparability of oxygenation values in the gastric tube assessed by HSI. In 1 of the 4 patients (patient 3 ), the NIR perfusion index was slightly higher in the oral part than in the aboral part, respectively to the resection line. The other 3 patients showed a lower or similar NIR perfusion index in the oral part than in the aboral part of the resection line. The intraoperative orientation of the camera differed between the different images (Fig. 1). However, this did not affect the oxygenation analysis of the gastric sleeve. This case series shows that the oxygenation is different in the gastric sleeve tissue. Therefore, the HSI technique could enable the surgeon to correct the location of the anastomosis due to quantitative assessment of tissue perfusion if oxygenation is insufficient. Although the intraoperative use of HSI was successful and surgical treatment of the patients was uneventful, prospective studies with large, convincing numbers of studied cases are needed to establish standard and cutoff values for the oxygenation parameters $\mathrm{StO}_{2}$ and the NIR perfusion index. As catecholamine treatment affects organ perfusion due to vasoconstriction, further studies should also account for the intraoperative catecholamine therapy and circulatory parameters, including arterial blood pressure, central venous pressure, and heart frequency, which were not addressed in this study. Another important aspect that should be considered for future studies is the standardized positioning of the ROI with identical distances between each ROI. This will improve the standardized oxygenation assessment as well as the comparability and the documentation of the gained data between different patients, respectively.

In summary, this is a proof-of-principle study that successfully illustrates and supports the promising use of intraoperative HSI technique for oxygenation assessment during esophageal resection in visceral surgery. In future, this technique could be a valuable tool to reduce the still relevant high incidence of anastomotic leakage that is associated to a significant increase in morbidity and mortality. 


\section{Acknowledgement}

The authors thank the patients for permitting the publication of their cases.

\section{Statement of Ethics}

The study was conducted ethically in accordance with the World Medical Association Declaration of Helsinki. The patient gave written informed consent to publish this case (including publication of the images).

\section{Disclosure Statement}

The authors have no conflicts of interest to declare.

\section{Funding Sources}

This study was self-funded.

\section{Author Contributions}

All authors planed the hyperspectral analysis in the presented case. F.S. and E.G. contributed to writing and drafting of the manuscript and performed the hyperspectral analysis.

\section{References}

1 Markar SR, Karthikesalingam A, Vyas S, Hashemi M, Winslet M. Hand-sewn versus stapled oesophago-gastric anastomosis: systematic review and meta-analysis. J Gastrointest Surg. 2011 May;15(5):876-84.

2 Saluja SS, Ray S, Pal S, Sanyal S, Agrawal N, Dash NR, et al. Randomized trial comparing side-to-side stapled and hand-sewn esophagogastric anastomosis in neck. J Gastrointest Surg. 2012 Jul;16(7):1287-95.

3 Marjanovic G, Hopt UT. [Physiology of anastomotic healing]. Chirurg. 2011 Jan;82(1):417. German.

4 Liebermann-Meffert DM, Meier R, Siewert JR. Vascular anatomy of the gastric tube used for esophageal reconstruction. Ann Thorac Surg. 1992 Dec;54(6):1110-5.

5 Yuan Y, Duranceau A, Ferraro P, Martin J, Liberman M. Vascular conditioning of the stomach before esophageal reconstruction by gastric interposition. Dis Esophagus. 2012 Nov-Dec;25(8):740-9.

6 Köhler H, Jansen-Winkeln B, Maktabi M, Barberio M, Takoh J, Holfert N, et al. Evaluation of hyperspectral imaging (HSI) for the measurement of ischemic conditioning effects of the gastric conduit during esophagectomy. Surg Endosc. 2019 Nov;33(11):377582.
7 Jansen-Winkeln B, Holfert N, Köhler H, Moulla Y, Takoh JP, Rabe SM, et al. Determination of the transection margin during colorectal resection with hyperspectral imaging (HSI). Int J Colorectal Dis. 2019 Apr; 34(4):731-9.

8 Jansen-Winkeln B, Maktabi M, Takoh JP, Rabe SM, Barberio M, Köhler H, et al. [Hyperspectral imaging of gastrointestinal anastomoses]. Chirurg. 2018 Sep;89(9):717-25. German.

9 Grambow E, Dau M, Holmer A, Lipp V, Frerich B, Klar E, et al. Hyperspectral imaging for monitoring of perfusion failure upon microvascular anastomosis in the rat hind limb. Microvasc Res. 2018 Mar;116:64-70.

10 Grambow E, Dau M, Sandkühler NA, Leuchter M, Holmer A, Klar E, et al. Evaluation of peripheral artery disease with the TIVITA $^{\circledR}$ Tissue hyperspectral imaging camera system. Clin Hemorheol Microcirc. 2019; 73(1):3-17.

11 Schlottmann F, Patti MG. Evaluation of Gastric Conduit Perfusion During Esophagectomy with Indocyanine Green Fluorescence Imaging. J Laparoendosc Adv Surg Tech A. 2017 Dec;27(12):1305-8.

12 Calin MA, Coman T, Parasca SV, Bercaru N, Savastru R, Manea D. Hyperspectral imagingbased wound analysis using mixture-tuned matched filtering classification method. J Biomed Opt. 2015 Apr;20(4):046004.
13 Daeschlein G, Langner I, Wild $\mathrm{T}$, von Podewils S, Sicher C, Kiefer T, et al. Hyperspectral imaging as a novel diagnostic tool in microcirculation of wounds. Clin Hemorheol Microcirc. 2017;67(3-4):467-74.

14 Fabelo H, Ortega S, Ravi D, Kiran BR, Sosa C, Bulters D, et al. Spatio-spectral classification of hyperspectral images for brain cancer detection during surgical operations. PLoS One. 2018 Mar;13(3):e0193721.

15 Fabelo H, Halicek M, Ortega S, Shahedi M, Szolna A, Piñeiro JF, et al. Deep LearningBased Framework for In Vivo Identification of Glioblastoma Tumor using Hyperspectral Images of Human Brain. Sensors (Basel). 2019 Feb;19(4):E920.

16 Promny D, Billner M, Reichert B. [Objective burn depth assessment of hand burns]. Handchir Mikrochir Plast Chir. 2019 Sep;51(5): 362-6. German.

17 Langner I, Sicher C, von Podewils S, Henning E, Kim S, Daeschlein G. [Hyperspectral imaging demonstrates microcirculatory effects of postoperative exercise therapy in Dupuytren's disease]. Handchir Mikrochir Plast Chir. 2019 Jun;51(3):171-6. German.

18 Holmer A, Marotz J, Wahl P, Dau M, Kämmerer PW. Hyperspectral imaging in perfusion and wound diagnostics - methods and algorithms for the determination of tissue parameters. Biomed Tech (Berl). 2018 Oct; 63(5):547-56 